\title{
O diário de bordo na formação inicial de professores de Química
}

\section{The logbook on the initial training of teachers of Chemistry}

\author{
Wallace Alves Cabral (wallacecabral@ufsj.edu.br) \\ Universidade Federal de São João del-Rei (UFSJ)
}

\begin{abstract}
Resumo: Atividades de leitura e escrita têm sido desenvolvidas com diferentes abordagens no âmbito da formação de professores de Ciências da Natureza. Ancorado nos pressupostos teóricos e metodológicas da Análise do Discurso de Linha Francesa (AD), esse artigo objetiva identificar as marcas de autoria em textos produzidos por licenciandos em Química da Universidade Federal de São João del-Rei (UFSJ) em MG. Os textos produzidos a partir dos diferentes gêneros textuais são chamados de diário de bordo, sendo esses construídos e apresentados no decorrer da unidade curricular Química e Sociedade. Mediante a construção do corpus de análise e do dispositivo teórico e analítico, uma categoria analítica emergiu. As análises mostraram que os diferentes diários possibilitaram o estabelecimento de várias relações inter, intra e extratextuais. Nesse sentido, os tipos de repetição (empírica, formal e histórica) foram apresentados, mostrando a necessidade de incentivo de diferentes ações na formação inicial de professores de Química para além do relatório técnico.
\end{abstract}

Palavras-chave: Escrita; AD; Química.

Abstract: Reading and writing activities have been developed with different approaches in the field of teacher training in Natural Sciences. Anchored in the theoretical and methodological assumptions of the French Line Discourse Analysis (DA), this article aims to identify the authorship marks in texts produced by chemistry graduates of the Federal University of São João del-Rei (UFSJ) in MG. The texts produced from the different textual genres are called logbooks, and these are built and presented during the course of the Chemistry and Society curricular unit. Through the construction of the corpus of analysis and of the theoretical and analytical device, an analytical category emerged. The analyzes showed that the different journals allowed the establishment of different inter, intra and extratextual relations. In this sense, the types of repetition (empirical, formal and historical) were presented, showing the need to encourage different actions in the initial training of Chemistry teachers in addition to the technical report.

Keywords: Writing; DA; Chemistry. 


\section{LEITURA E ESCRITA NA FORMAÇÃO INICIAL DE PROFESSORES DE QUÍMICA}

Atividades e reflexões sobre a linguagem na formação inicial de professores de Ciências/Química têm sido frequentemente apresentadas por diferentes pesquisadores da área (NASCIMENTO; CASSIANI, 2009; ALMEIDA; SORPRESO, 2010; DIAS; ALMEIDA, 2010; NASCIMENTO; MARTINS, 2011; QUADROS, SILVA; SILVA, 2011; FERREIRA; QUEIROZ, 2012; AUTOR, 2015; AUTOR, 2016; PALCHA, 2016; AUTOR, 2017; FRANCISCO JUNIOR; GAMA, 2017; AUTOR, 2018). Nesses trabalhos, diversas perspectivas em torno do papel da leitura e da escrita são utilizadas. Entretanto, apresentarei apenas os artigos que são balizados pelo mesmo referencial teórico e metodológico adotado nesta pesquisa, no caso, a Análise do Discurso de Linha Francesa $(\mathrm{AD})$ com os trabalhos de Eni Orlandi no Brasil. Apesar desse referencial não ter um enfoque especial para o Ensino de Ciências, suas pesquisas são de grande contribuição para a compreensão do papel linguagem nessa área de conhecimento.

Para a $\mathrm{AD}$, o discurso é produzido na articulação de dois grandes processos: a paráfrase e a polissemia. O processo parafrástico é aquele que permite a produção do mesmo sentido de diferentes formas e o processo polissêmico é o responsável pelo fato de que são possíveis outros sentidos. Dessa forma, existe um retorno ao dizer sedimentado, a reprodução - a paráfrase - e, em outro ponto, temos o rompimento com esse dizer, dispondo-se da multiplicidade, do diferente (ORLANDI, 2015).

Ainda para Orlandi (2012), a autoria se realiza toda vez que o produtor da linguagem se encontra produzindo um texto com unidade, coerência, progressão e fim. Sendo responsável pelo que diz ou escreve, embora se constitua na repetição (interdiscurso), historicizando seu dizer. Em textos escritos, podemos perceber a autoria por ser uma forma material da relação com o simbólico. Os processos de autoria podem acontecer de diferentes maneiras, a partir da repetição empírica, repetição formal ou repetição histórica.

a) A repetição empírica (mnemônica) que é a do efeito papagaio, só repete;

b) A repetição formal (técnica) que é um outro modo de dizer o mesmo;

c) A repetição histórica, que é a que desloca, a que permite o movimento porque historiciza o dizer do sujeito (ORLANDI, 2012, p. 54) [...]. 
Nesse processo de autoria, as relações de sentido não se constituem exclusivamente entre o leitor e o texto, e sim, "no espaço discursivo dos interlocutores" (ORLANDI, 2006), ou seja, na interação entre o leitor real e o virtual. O leitor virtual é designado como o "leitor imaginário, aquele que o autor imagina (destina) para seu texto e para quem ele se dirige. Tanto pode ser um seu 'cúmplice' quanto um seu 'adversário"” (ORLANDI, 2012, p.10). Podemos, então, dizer que as relações “[...] entre os interlocutores desencadeia, por meio de uma historicidade da leitura, uma tessitura de sentidos que carrega e determina o conjunto de significações" (PALCHA; OLIVEIRA, 2014, p. 102).

Investigando os sentidos atribuídos a uma revista de divulgação científica, Dias e Almeida (2010) realizaram uma pesquisa com um grupo de licenciandos em Física. A revista selecionada foi a Ciência Hoje e Pesquisa Fapesp, sendo trabalhada com alunos ingressantes na licenciatura em Física durante a disciplina Conhecimentos em Física Escolar I. Os resultados indicaram os diferentes modos de leitura e diversos tipos de repetições pelos alunos.

[...] a formal, nos momentos em que os licenciandos se detiveram no texto, verbalizando-o com as próprias palavras; a empírica, quando notamos a repetição "papagaio" de uma analogia do texto; e a histórica, quando encontramos indícios da inscrição de alguns licenciandos em uma rede de filiações ligadas à sua memória discursiva, principalmente em aspectos sociais da práxis científica (DIAS; ALMEIDA, 2010, p. 61).

No âmbito da formação de professores de Química, Cabral e Flôr (2016) propuseram atividades de leitura e escrita no âmbito do Estágio Supervisionado. Buscando o afastamento do gênero comumente utilizado nessa disciplina, no caso o relatório, os pesquisadores apoiaram-se na produção de relatos, "que se configuram como um documento pessoal, na qual são abordados assuntos relevantes sobre o trabalho ou a observação que está sendo feita" (p. 165). Para os estagiários dessa pesquisa, ficou marcado a preferência pela produção de relatos ao invés do relatório técnico, apesar da dificuldade encontrada em expor as suas ideias e do movimento de criação exigido.

Enquanto professor no Ensino Superior, observo que nas produções textuais dos licenciandos em Química, de modo geral, há uma repetição do já dito, ou seja, "retorno aos mesmos espaços do dizer" (ORLANDI, 2012, p. 23). Isso é muito frequente nos 
relatórios, pois o engessamento que esse gênero textual confere dificulta que o estudante transite e estabeleça diferentes relações intertextuais com outras formações discursivas (AUTOR 1, 2015).

Com relação a intertextualidade, esse é um dos princípios que regulam o discurso. Tal fato ocorre quando um texto estabelece relação com outros textos (possíveis, existentes ou imaginários). Os sentidos que são lidos em um texto não estão necessariamente nele, ou seja, o(s) sentidos(s) de um texto passa(m) pela relação dele com outros textos (ORLANDI, 2012). Esse fato revela a complexidade do processo de leitura, "saber ler é saber o que o texto diz e o que ele não diz, mas o constitui significativamente" (p. 13).

\begin{abstract}
A intertextualidade stricto sensu [...] ocorre quando, em um texto, está inserido outro texto (intertexto) anteriormente produzido, que faz parta da memória social de uma coletividade ou da memória discursiva (domínio estendido de referência, cf. Garrod, 1985) dos interlocutores. Isto é, em se tratando de intertextualidade, é necessário que o texto remeta a outros textos ou fragmentos de textos efetivamente produzidos, com os quais estabelece algum tipo de relação (KOCH, BENTES; CAVALCANTE, 2012, p. 17).
\end{abstract}

Fazendo uso desse conceito na perspectiva da AD, Ribeiro, Munford e Perna (2012) analisaram as práticas de licenciandos que atuaram como professores em um projeto de Educação de Jovens e Adultos (EJA).

\begin{abstract}
Os resultados indicam a importância do resgate de suas histórias de leitura como indicavam estudos anteriores. Além disso, nossas análises evidenciam que ser professor em salas de aula com alunos afastados da escola há vários anos exigiu transformações nas suas práticas de leitura com a valorização de aspectos de diferentes noções de intertextualidade. Acreditamos que a continuidade de estudos e intervenções no contexto da formação inicial de professores é extremamente importante (p. 148).
\end{abstract}

A partir dessa construção teórica em torno dos trabalhos que buscam aporte na $\mathrm{AD}$, esse artigo apresenta uma atividade de leitura e escrita desenvolvida com os licenciandos em Química da Universidade Federal de São João del-Rei (UFSJ) e tem como objetivo principal:

- Identificar as marcas de autoria e das relações intertextuais nos textos produzidos por licenciandos em Química.

\title{
2. CAMINHOS METODOLÓGICOS
}


Esta é uma pesquisa com abordagem qualitativa sustentada pelo referencial da $\mathrm{AD}$, que objetiva analisar os textos produzidos em diferentes aulas por licenciandos em Química. O referencial adotado vai de encontro com a visão empirista da ciência, que pressupõe um objeto estático, tendo uma única verdade que será descoberta após a sistematização e coleta de dados. As construções metodológicas e analíticas compreendem o posicionamento em determinado lugar, não neutro, pois não segue critérios empíricos (positivistas).

Essa não neutralidade "baseia-se no fato de que, nesse movimento de construção do corpus, há um posicionamento teórico declarado. É importante não confundí-la com alguma forma de 'coleta de dados' levada a cabo de forma displicente ou não comprometida" (FLÔR, 2009, p. 98).

Compreendo, a partir da perspectiva discursiva, que as condições de produção englobam os sujeitos e a situação (estrito e amplo). Sabe-se que as condições de produção, “em um sentido estrito temos as circunstâncias da enunciação: é o contexto imediato. E se as consideramos em sentido amplo, as condições de produção incluem o contexto sócio-histórico, ideológico" (ORLANDI, 2012, p. 30). Apesar dessa distinção para fins de explicação, na prática, não é possível dissociar um do outro, "em todas as situações de linguagem esses contextos funcionam conjuntamente" (ORLANDI, 2015, p. 17). Nesse sentido, apesar do enfoque em apenas uma atividade, tenho compreensão que essa se insere em um contexto mais amplo, marcado por diferentes relações/interações.

Ao longo do segundo semestre letivo de 2018, na unidade curricular intitulada Química e Sociedade do curso de Licenciatura em Química da UFSJ em MG, diferentes diários de bordo foram produzidos. Essa é uma disciplina obrigatória da matriz curricular do $7^{\circ}$ período do curso e tem como um dos objetivos fomentar $\mathrm{o}$ posicionamento crítico frente aos problemas sociais a partir das lentes da Química.

Dentre as atividades avaliativas da disciplina, temos o diário de bordo, que consiste no registro dos acontecimentos e discussões de uma aula por um grupo de estudantes. Então, no início da aula seguinte, o diário de bordo é apresentado pelo grupo. Esse texto pode ser apresentado a partir dos diferentes gêneros textuais, sendo a escolha definida pelo grupo. Essa dinâmica se repete em todas as aulas, até que todos os 
alunos (ou grupos) tenham feito ao menos uma vez o diário de bordo. No semestre em questão, havia 23 estudantes matriculados, logo, foram formados 12 duplas e 1 trio, sendo que cada grupo ficou responsável por apresentar apenas um diário de bordo.

O diário de bordo é sempre apresentado no início da próxima aula, na tentativa de criar um elo entre a aula que se findou e a que iniciará. Cabe ressaltar que em nenhum momento foi indicado que não poderia existir repetição de gênero textual entre os grupos. Pelo contrário, a orientação era no sentido de que cada grupo criasse o diário de bordo a partir do gênero textual de maior interesse. Esse diário é apresentado em cada aula, sendo impresso pelo docente e entregue para cada estudante. Após a leitura em sala de aula, sugestões de melhorias são recomendadas, tanto em relação ao conteúdo quanto a correção ortográfica. Ou seja, correções ortográficas são apontadas, discussões que não foram abordadas são sugeridas para acréscimo e ajustes em torno do gênero textual também são considerados. Diante dessas recomendações feitas pelos alunos e docente, o grupo responsável elabora uma versão final que é postada no espaço virtual da disciplina.

Quadro 1 - Gênero textual selecionado para apresentação de cada diário de bordo.

\begin{tabular}{|c|c|}
\hline AULA & GÊNERO TEXTUAL \\
\hline 1 & Jornal \\
\hline 2 & E-mail \\
\hline 3 & Ata \\
\hline 4 & Lei \\
\hline 5 & Sinopse \\
\hline 6 & Informativo \\
\hline 7 & Manual de instrução \\
\hline 8 & Poema \\
\hline 9 & Carta \\
\hline 10 & Vídeo \\
\hline 11 & Histórias em quadrinhos \\
\hline
\end{tabular}

Fonte: elaborado pelo autor.

Tal como pode ser visto no Quadro 1, diversos gêneros textuais foram utilizados para apresentar o diário de bordo. A concepção de texto aqui adotada é oriunda da AD. 
O texto tem sempre uma finalidade: entrar no sistema da comunicação. Assim ele passa a ser enunciado, produzido por um enunciador, sujeito histórico situado, que entra na comunicação, ou seja, apresenta-se, revela-se na enunciação. Além disso, podemos dizer que ele não é delimitado por sua extensão, e também, ser escrito ou oral não muda a definição de texto. Os textos (os gêneros textuais) realizam discursos em situações institucionais, históricas, sociais e ideológicas (BRANDÃO, 2012; ORLANDI, 2012).

\title{
2.1 O CORPUS DE ANÁliSE E O DISPOSITIVO TEÓRICO E ANALÍTICO
}

O corpus de análise se constitui a partir de três diários de bordo destacados em negrito no Quadro 1. Dentro disso, penso que esses diários se constituem como um texto, sendo "[...] a unidade que o analista tem diante de si e da qual ele parte. [...]? Ele o remete imediatamente a um discurso que, por sua vez, se explicita em suas regularidades pela sua referência a uma ou outra formação discursiva" (ORLANDI, 2012 p. 63).

\begin{abstract}
A análise é um processo que começa pelo próprio estabelecimento do corpus e que se organiza face à natureza do material e à pergunta (ponto de vista) que o organiza. Daí a necessidade de que teoria intervenha a todo momento para "reger" a relação do analista com o seu objeto, com os sentidos, com ele mesmo, com a interpretação (p. 64).
\end{abstract}

As condições em que o discurso é produzido, considerando o contexto social e histórico, a ideologia, o local de onde o sujeito fala, as relações de forças e sentido, entre outros mecanismos do discurso, apontam o modo como os sentidos são produzidos. Cabendo ao analista do discurso utilizar desses pressupostos teóricos para ultrapassar as barreiras do efeito-leitor, entendendo como os objetos simbólicos produzem sentidos, fazendo com que esse dispositivo coloque

[...] o dito em relação ao não dito, o que o sujeito diz em um lugar com o que é dito em outro lugar, o que é dito de um modo com o que é dito de outro, procurando ouvir, naquilo que o sujeito diz, aquilo que ele não diz mas que constitui igualmente os sentidos de suas palavras (ORLANDI, 2012, p. 59).

O dispositivo teórico - "constituído pelas noções e conceitos que constituem os princípios da análise de discurso" (ORLANDI, 2015, p. 29) - orienta o dispositivo 
analítico. Esse permite ao analista observar o funcionamento discursivo, indo além de uma leitura tradicional, sendo uma leitura sintomática, "a que estabelece uma escuta que coloca em relação o dizer com outros dizeres e com aquilo que ele não é mas poderia ser" (IDEM, p. 30).

Os conceitos de autoria e intertextualidade, que constituem o dispositivo teórico, já foram discutidos ao longo deste artigo. Diante disso, o dispositivo analítico é construído pelo pesquisador na análise específica a partir do dispositivo teórico.

Definido o dispositivo analítico, compreendo a impossibilidade de exaustão horizontal em relação ao objeto de estudo, "isto porque, por definição, todo discurso se estabelece na relação com um discurso anterior e aponta para outro. Não há discurso fechado em si mesmo, mas um processo discursivo do qual se podem recortar e analisar estados diferentes" (ORLANDI, 2012, p. 62). Porém, a exaustividade vertical é almejada a partir da questão de pesquisa e dos objetivos, podendo gerar uma profundidade teórica. Para isso, o corpus de análise precisa estar bem delimitado e definido, "a construção do corpus e a análise estão intimamente ligadas: decidir o que já faz parte do corpus já é decidir acerca de propriedades discursivas” (IBIDEM, p. 63).

Partindo do processo de de-superficialização (ORLANDI, 2012) e da construção do disposto analítico, uma categoria de análise emergiu, tal como será apresentada a seguir.

\section{ANALISANDO ALGUNS DIÁRIOS DE BORDO}

Em virtude do número de diários de bordo construídos (Quadro 1) e da limitação do espaço para produção deste artigo, somente 3 textos foram selecionados de maneira aleatória para análise.

O primeiro diário de bordo analisado é referente a aula 3 e foi apresentado no início da aula 4. Tal texto foi exibido no formato de lei, como pode ser visto na Figura 1. De imediato, cabe ressaltar que os diferentes elementos que caracterizam esse gênero textual foram atendidos, como o número da lei, data da publicação, ementa (descrição da lei), conteúdo (organizado por artigos, parágrafos, incisos, seções e alíneas), local e assinatura. Além desses itens, é perceptível a adequação da linguagem ao gênero 
utilizado. Termos como "sanciono", "caput" e "decretar" são característicos de uma lei, portanto houve um cuidado com a utilização da linguagem.

$\mathrm{Na}$ aula relatada no diário de bordo, houve a discussão do artigo de Santos e Mortimer (2001), trazendo para o debate questões sobre a perspectiva da Ciência, Tecnologia e Sociedade (CTS) e a importância da tomada de decisão por diferentes sujeitos. Nesse sentido, "a lei” apresentada traz com pertinência diferentes elementos das discussões que aconteceram, por exemplo:

\footnotetext{
"a tomada de decisão nos currículos CTS é vista por alguns autores como um processo racional que envolve várias etapas: opções, critérios, informação, pesquisa, escolha e revisão”.

"fica evidenciado que todos os modelos apresentados no texto comprovam uma forma racionalista de encarar a tomada de decisão".

"Uma educação científica que se pretende neutra é ideologicamente tendenciosa”. (FRAGMENTOS DO DIARIO DE BORDO 4).
}

Esses e outros fragmentos reforçam as diferentes relações intertextuais que foram estabelecidas em sala de aula, havendo um resgate das histórias de leituras dos sujeitos, indo além do texto recomendado. Um indicativo disso está nos artigos 5 e 6 , em que são apresentados problemas sociais e a relação com o filme "Saneamento Básico", respectivamente. Esses problemas e a produção audiovisual foram desencadeadas a partir das discussões do texto de Santos e Mortimer (2001).

Analisando os movimentos de autoria nessa produção textual, percebo que há um trânsito entre os três tipos de repetição. Ou seja, na repetição empírica há cópias do texto lido, "[...] a passagem da "repetição empírica", quando o estudante exercita a memória para dizer apenas aquilo que o professor ou o livro já havia dito (num mero exercício mnemônico)" (ALMEIDA, CASSIANI; OLIVEIRA, 2008, p. 40). Como exemplo, apresento o fragmento a seguir:

No presente artigo apresentamos as principais contribuicões das pesquisas sobre currículos em CTS com relação ao seu objetivo central de formação da cidadania para uma ação social responsável (SANTOS; MORTIMER, 2001, p. 95).

Fica explicitado as principais contribuições das pesquisas sobre currículos em CTS com relação ao seu objetivo central de formação da cidadania para uma ação social responsável (Fragmento do diário de bordo 4). 
Em outros momentos, tal como pode ser visto no exemplo abaixo, o grupo apenas escreve com outras palavras aquilo que foi discutido sobre o texto lido, aproximando da repetição formal. "Nesse tipo de repetição, o estudante explicita as mesmas ideias vistas nas aulas, mas com outra roupagem, ou seja, repete o que foi dito com outras palavras" (ALMEIDA, CASSIANI; OLIVEIRA, 2008, p. 40).

Ao se pensar em currículos de ciência com o objetivo de formação para a cidadania, é fundamental que seja levado em conta o desenvolvimento da capacidade de tomada de decisão (SANTOS; MORTIMER, 2001, p. 107).

Os currículos de ciência que objetivam trabalhar na perspectiva CTS devem considerar a importância da tomada de decisão pelo indivíduo (Fragmento do diário de bordo 4).

A repetição histórica, diferentemente das demais apresentadas, engloba uma rede de filiações ligadas à memória discursiva, trazendo elementos que não estão conectados a uma leitura específica. Além disso, apenas nessa repetição o indivíduo se torna autor, trabalhando na relação do interdiscurso com o interlocutor. Ao investigar o diário apresentado na Figura 1, observa-se que a repetição histórica é a que menos aparece. No fragmento sublinhado a seguir é possível observar o posicionamento do grupo frente ao exposto, trazendo elementos que não emergiram exclusivamente de uma leitura, ou seja, houve um resgate da memória discursiva.

Os currículos devem ser estruturados de tal forma a propiciar condições para que os alunos desenvolvam os passos da tomada de decisão. Para isso, acredita-se que seja de fundamental importância que o professor reconheça qual é seu papel em sala de aula, indo além da reprodução de conceitos estanques. (Fragmento do diário de bordo 4).

Fonte: produzido pelo grupo 4. 
Lei ${ }^{\circ} 2.308$, de 23 de Agosto de 2018

Dispõe sobre estímulos de desenvolvimento científico $e$ tecnológico, o letramento cientifico, bem como a tomada de decisão para ação responsável no Ensino de Ciência, à cidadania, à responsabilidade social para que os alunos possam atuar como cidadãos ativos nas decisões e agindo com encargo igualitário.

\section{O PROFESSOR Faço saber que o Laboratório de Ensino decreta e eu sanciono a seguinte} Lei:

Art. $1^{\circ}$ Extensão CTS e a Tomada de decisão: apóia esta incumbência como principal meta preparar os alunos para o exercício

$\S 1^{\circ}$ fica explicitado às principais contribuições das pesquisas sobre os currículos em CTS com relação ao seu objetivo central de formação cidadã em uma ação social responsável.

$\S 2^{\circ}$ é apresentado o significado e as implicações educacionais desse objetivo e os resultados de pesquisas em tomo da capacidade de tomada de decisão que tem um processo fundamental na formação da cidadania.

$\S 3^{\circ}$ a tomada de decisão nos currículos CTS é vista por alguns autores como um processo racional que envolve várias etapas: Opções, Critérios, Informação, Pesquisa, Escolha e Revisão.

$\S 4^{\circ}$ etapas de questionamento é extremamente importante no processo de solução de um problema e de tomada de decisão. Os currículos devem ser estruturados de tal forma a propiciar condições para que os alunos desenvolvam os passos da tomada de decisão.

$\S 5^{\circ}$ fica evidenciado que todos os modelos apresentados no texto comprovam uma forma racionalista de encarar a tomada de decisão. As decisões sobre as interações entre ciência e tecnologia e a sociedade podem ser tomadas de acordo com os modelos tecnocráticos, decisionistas e pragmáticopolítico.

Art. $2^{\circ}$ _Uma educação cientifica que se pretende neutra é ideologicamente tendenciosa.

Art. $3^{\circ}$._ bônus aos CTS's: atividade que auxilia no desenvolvimento, no aperfeiçoamento e na difusão de soluções tecnológicas e na sua disponibilização à sociedade e à ciência.

$\S 1^{\circ}$ fica explicitado o compartilhamento das experiências abordando problemas sócioambientais, bem como o envolvimento das CTS's na solução e desenvolvimento do problema, promovendo a cooperação e interação entre os entes presentes nesta sessão.

Figura 1: Parte do diário de bordo referente a aula 3.

Na aula 7 dessa mesma disciplina, foram realizadas dinâmicas e leituras em torno da temática "Direitos Humanos na Educação Química". Nesse sentido, o grupo 8 criou um diário de bordo por meio de um poema, tal como pode ser visto na Figura 2.

Fonte: produzido pelo grupo 8 . 
HUMANO DIREITO

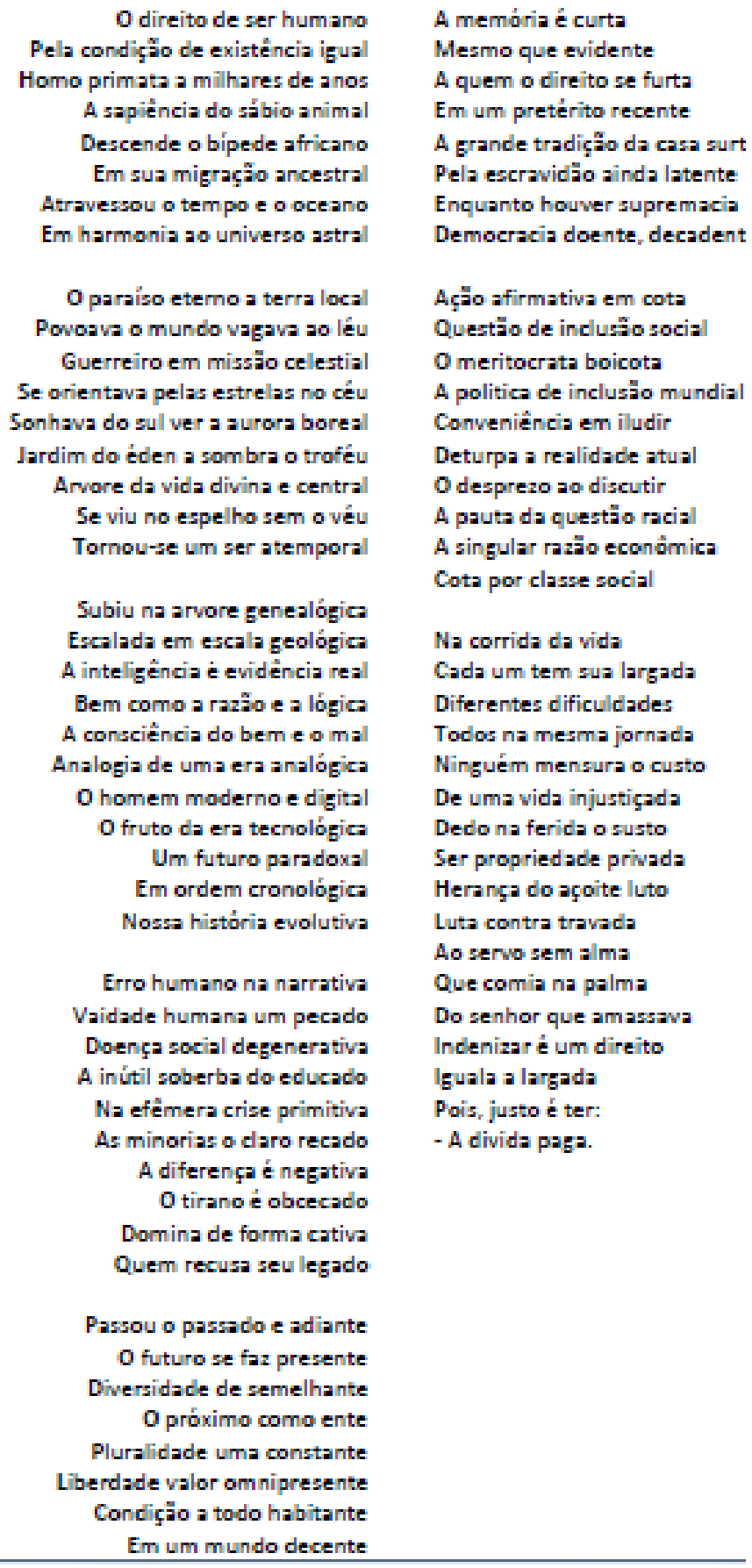

Figura 2: Diário de bordo referente a aula 7.

Assim como o diário de bordo apresentado na figura 1, os elementos intrínsecos a esse gênero textual são contemplados, tal como a composição de versos e a busca por sensibilizar o leitor entorno das questões postas. Nesse processo, diferentes relações intertextuais são evidenciadas, como a história e colonização do nosso país, 
meritocracia, cota social, racismo e luta das minorias. Tais elementos foram discutidos ao longo da aula, emergindo de vivências dos acadêmicos em torno dos preconceitos já sofridos.

Cabe ressaltar que o gênero textual escolhido pelo grupo dificulta a cópia (repetição empírica), pois, ao construir um poema, envolve com maior intensidade a imaginação e criação. Nessa direção, Colello (2012) destaca que o estudante que é produtor de textos tem o desafio da produção da escrita e, ao mesmo tempo, a satisfação de poder dar vida aos seus pensamentos, às suas ideias e fantasias.

Palcha e Oliveira (2014), ao envolverem licenciandos em Ciências Biológicas em atividades de leitura e escrita em torno de um conto literário, denotaram aspectos extratextuais (manifestação cultural, social e científica), intratextuais (criação, imaginação, personagens) e intertextuais (relação com outros textos) nos textos produzidos pelos alunos. No que tange ao diário de bordo apresentado na Figura 2, pode-se perceber que elementos extra e intratextuais são mais contemplados, consequentemente, fomentando a repetição histórica. Nesse tipo de repetição, existe a incorporação do sentido próprio pelo sujeito a memória constitutiva, ou seja, os alunos passaram a assumir o discurso como seu. Não há marcas de cópias ou processos parafrásticos dos textos lidos, e sim, sinais dos discursos sedimentados que foram construídos ao longo da aula.

Por fim, apresento o diário de bordo construído a partir de um gênero textual instrucional. Conforme pode ser visto na Figura 3, o grupo apresentou os principais elementos da aula 6 por meio de um passo a passo, típico de um manual. Complementando o texto, diferentes especificações foram dadas, no sentido de nortear o leitor sobre o ocorrido na aula anterior. Esse processo em que os estudantes constroem um texto pensando nos possíveis sentidos para o seu interlocutor é chamado de mecanismo de antecipação. "Segundo o mecanismo de antecipação, todo sujeito tem a capacidade de experimentar, ou melhor, de colocar-se no lugar em que o seu interlocutor "ouve" suas palavras. Ele antecipa-se assim a seu interlocutor quanto ao sentido que suas palavras produzem" (ORLANDI, 2012, p. 39). Nesse processo, o leitor virtual é designado, sendo aquele idealizado pelo autor, buscando delimitar os sentidos para compreensão do que está sendo apresentado. 
Fonte: produzido pelo grupo 7.

\section{MANUAL DE INSTRUÇÃO PARA UMA AULA SOBRE QSC}

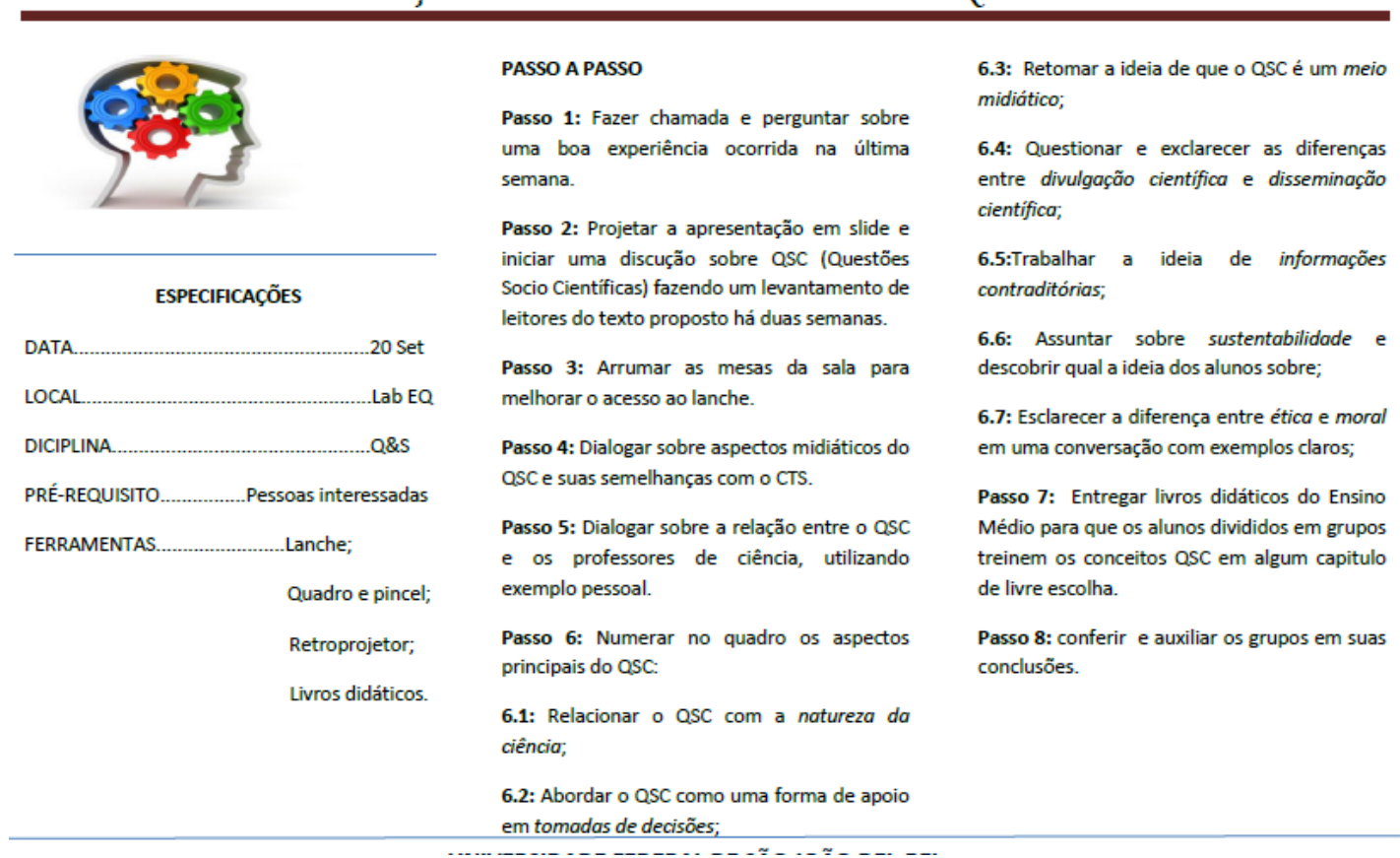

Figura 3: Parte do diário de bordo referente a aula 6.

Nesse movimento em que o estudante se antecipa com relação aos possíveis sentidos, diferentes elementos da aula são apresentados. Como podem serem vistos, pontos das questões sociocientíficas emergem: mídia, natureza da ciência, tomada de decisão, divulgação científica e disseminação científica, sustentabilidade e, por fim, questões éticas e morais. Esses temas foram discutidos na aula e pensados no papel do professor de Química frente às questões controvérsias. Entretanto, ao investigar a autoria neste diário, esse é marcado pela repetição formal, ou seja, o grupo apresentou com outras palavras os tópicos construídos e apresentados no quadro branco em sala de aula, sintetizados nos passos 5 e 6 do manual de instrução.

Cabe destacar que os diários aqui analisados têm uma forma predominante de repetição e, devido a isso, não pode ser considerada a única. Concordo com a pesquisa de Flôr (2015), que aponta que "ao invés de polarizar entre um ou outro tipo de repetição, busquei os nuances do que ocorre entre esses extremos, que não são absolutos” (p. 12). Sendo assim, é possível notar que a forma predominante de repetição 
pode variar de acordo com as experiências dos sujeitos e, principalmente, em virtude do gênero textual utilizado.

Tal como apresentado por Cabral e Flôr (2016), o gênero textual relatório é predominantemente utilizado na formação de professores de Química. A crítica não consiste na utilização desse gênero textual na formação de professor, e sim, na ênfase indevida que é dada a ele. Para os pesquisadores, o foco nesse gênero dificulta que o estudante estabeleça diferentes relações intertextuais, bem como transite por elementos intra ou extratextuais. Nesse sentido, é possível associar que esse gênero dificulta a repetição histórica, característica esperada em um futuro professor de Química.

Além disso, defendo que o professor de Química deva incentivar e propor diferentes atividades de leitura e escrita, minimizando a responsabilidade que é atribuída exclusivamente ao professor de Língua Portuguesa. Para isso, é importante que esse futuro docente vivencie e reflita sobre a linguagem em sua formação, para que, com maior pertencimento e propriedade, possa incentivar tais práticas na Educação Básica.

\section{ALGUMAS CONSIDERAÇÕES}

O diário de bordo na formação de professores se constitui em um importante instrumento de resgate das discussões ocorridas na aula anterior, trazendo o estudante para reflexão sobre o que foi discutido, além de sanar possíveis dúvidas. Somado a isso, há uma aproximação dos diferentes gêneros textuais com os estudantes, uma vez que o diário de bordo não tem um gênero definido. E, ao mesmo tempo, fomenta atividades de leitura e escrita em aulas de Química, distanciando da visão de que ações que envolvam ler e escrever é de responsabilidade exclusiva do docente de Língua Portuguesa.

Para além desses apontamentos, ao analisar os 3 diários produzidos por diferentes licenciandos em Química, é perceptível que os alunos conseguiram trabalhar com diferentes gêneros textuais, enquadrando-os dentro do contexto de estudo. Nesses textos, algumas relações intertextuais são estabelecidas, seja por leituras oriundas da própria disciplina ou pelo seu histórico de leituras.

Por fim, ressalto que não tive a intenção de apresentar todos os trechos que apresentam à repetição empírica, formal ou histórica, e sim, busquei discutir como esses 
gestos significam no âmbito desses relatos. Com relação a esses processos, observa-se que não há uma repetição dominante entre os diários de bordo, variando de acordo com o grupo e gênero textual utilizado. Como indicativo para trabalhos futuros, cabe avaliar e incentivar nesses textos movimentos que priorizam a repetição histórica.

\section{REFERÊNCIAS}

ALMEIDA, M. J. P. M; CASSIANI, S; OLIVEIRA, O. B. Leitura e escrita em aulas de Ciências: luz, calor e fotossíntese nas mediações escolares. Florianópolis: Letras contemporâneas, 2008.

ALMEIDA, M. J. P. M; SORPRESO, T. P. Memória e formação discursivas na interpretação de textos por estudantes de licenciatura. Revista Brasileira de Pesquisa em Educação em Ciências. São Paulo, v.10, n.1, 2010.

BRANDÃO, H. N. Enunciação e construção do sentido. São Paulo: Contexto, 2012.

CABRAL, W. A; FLÔR, C. C. C. (Re)pensando as práticas de escrita na disciplina de Estágio Supervisionado em Química: com a palavra, os estagiários. Ensaio. Belo Horizonte, n. 3, v. 18, p.51-64, 2016.

COLELlO, S. M. A escola que (não) ensina a escrever. 2. ed. São Paulo: Summus, 2012.

DIAS, R. H. A; ALMEIDA, M. J. P. M. A repetição em interpretações de licenciandos em física ao lerem as revistas Ciência Hoje e FAPESP. Ensaio. Belo Horizonte, n. 3, v. 12, p.51-64, 2010.

FERREIRA, L. N. A.; QUEIROZ, S. L. Perguntas elaboradas por graduandos em Química a partir da leitura de textos de divulgação científica. Revista Brasileira de Pesquisa em Educação em Ciências, São Paulo, v.12, n.1, p. 139-160, 2012.

FLÔR, C. C. Leitura e formação de leitores em aulas de química no ensino médio. Tese de doutorado. PPGECT/UFSC. 2009.

Movimentos de repetição na formação de leitores em aulas de química no Ensino Médio. In: Anais da 37ª Reunião Nacional da ANPEd, Florianópolis, 2015.

FRANCISCO JUNIOR, W. E; GAMA, E. J. S. História em quadrinhos para o Ensino de Química: contribuições a partir da leitura de licenciandos. Revista Electrónica de Enseñanza de las Ciencias. V. 16, n.1, p. 152-172, 2017.

KOCH, I. G. V; BENTES, A. C; CAVALCANTE, M. M. Intertextualidade: diálogos possíveis. São Paulo: Cortez Editora, 2012. 
NASCIMENTO, T. G; MARTINS, I. Leituras de textos da Revista Ciência em Tela por professores de Ciências. Ensaio. Belo Horizonte, n. 3, v.13, p.207-230, 2011.

NASCIMENTO, T. G; CASSIANI, S. Leituras de divulgação científica por licenciandos em Ciências Biológicas. Revista Electrónica de Enseñanza de las Ciencias. n. 3, v. 8, p. 745-769, 2009.

ORLANDI, E.P. Análise de Discurso: princípios e procedimentos. 10.ed. Campinas, Pontes Editores, 2012.

Análise de Discurso. In: ORLANDI, E. P; LAGAZZI-RODRIGUES, S. (org.) Discurso e textualidade, Campinas: PONTES, 2015, p. 13-35.

2006.

A linguagem e seu funcionamento: as formas do discurso. São Paulo: Pontes,

PALCHA, L. S. O efeito-leitor na mediação de conhecimentos do estágio: uma análise dos discursos de licenciandos em Ciências Biológicas. Tese de doutorado. PPGGE/UFPR. 2016.

PALCHA, L. S; OLIVEIRA, O. B. A evolução do ovo: quando leitura e literatura se encontram no Ensino de Ciências. Ensaio. v.16, n.1, p. 101-114, 2014.

QUADROS, A. L; SILVA, D. C; SILVA, F. C. Formulação de questões a partir da leitura e um texto: desempenho dos estudantes de Licenciatura em Química da modalidade a distância. Ensaio. Belo Horizonte, v. 13, n. 1, p. 43-56, 2011.

RIBEIRO, N. A; MUNFORD, D; PERNA, G. P. A. Experiências de leitura em Ciências da natureza na Educação de Jovens e Adultos: um estudo das práticas de professores formação inicial. Revista Brasileira de Pesquisa em Ensino de Ciências. v. 12, n.2, p. 129-151, 2012.

SANTOS, W. L. P; MORTIMER, E. F. Tomada de decisão para ação social responsável no Ensino de Ciências. Ciência e Educação. v. 7, n. 1, p. 95-111, 2001. 